\title{
DINAMIKA KEPENDUDUKAN DAN KETENAGAKERJAAN INDONESIA
}

\section{POPULATION AND LABOUR FORCES DYNAMICS IN INDONESIA}

\author{
Prijono Tjiptoherijanto \\ Lembaga Demografi FE - Universitas Indonesia
}

\begin{abstract}
Abstrak
Persoalan kependudukan dan ketenagakerjaan di Indonesia akan semakin kompleks dimasa mendatang. "Bonus Demografi" yang telah dinikmati semenjak awal periode tahun 2000-an akan membuka "Window of Opportunity" pada tahun 2030-2035, tidak lama lagi dari saat ini. Sementara itu Indonesia juga akan mengalami era penduduk lanjut usia mulai tahun 2030. Dengan konsentrasi penduduk di daerah perkotaan Jawa, perencanaan kependudukan yang dikaitkan dengan berbagai aspek perekonomian lain, perlu mendapat perhatian lebih serius. Terutama upaya peningkatan kualitas manusia yang di perlukan sebagai faktor penggerak utama dari pertumbuhan ekonomi tetap perlu diupayakan.
\end{abstract}

Kata kunci: bonus demografi, window of opportunity

\section{Abstract}

Population and labour forces problems in Indonesia will need serious attention in the near future. Particularly with regards to the "demographic devident', which was experienced since the beginning of 2000. The 'window of opportunity" which occurred in the period of 20302035 should be managed carefully in order to give benefit to the Indonesian economy in the future. While effort to increase human resources quality is a must, the rate of urbanization, especially in Java's island should be given more carefull attention by the policymakers in the field of population and development.

Keywords: demographic devident, window of opportunity

\section{A. Pendahuluan}

Mega trend soal kependudukan Indonesia sekarang yakni: pertama, besarnya jumlah penduduk dan pertumbuhan penduduk yang belum mencapai kondisi ideal. Apabila pertambahan penduduk Indonesia masih pada tingkat seperti sekarang ini (kelahiran sekitar 2,6 jauh di atas angka ideal 2,1) maka penduduk Indonesia diperkirakan akan mencapai sekitar 340 juta pada tahun 2050 dan 420 juta pada tahun 2010 (proyeksi penduduk yang di buat oleh UN 2010). Ini tentu saja berdampak pada kondisi kependudukan global karena berdasarkan analisis UN Indonesia merupakan satu dari 5 (lima) negara sebagai penyumbang pertumbuhan penduduk dunia sampai dengan tahun 2050 bersama dengan India, Pakistan, Brazil dan Nigeria. Jumlah penduduk yang besar itu akan berpengaruh juga kepada tenaga kerja dan angkatan kerja yang ada. Jumlah tenaga kerja saat ini dapat dilihat pada Tabel 1. 
Tabel 1. Jumlah Tenaga Kerja 2009-2013

\begin{tabular}{|l|r|r|r|r|r|}
\hline & \multicolumn{1}{|c|}{2009} & \multicolumn{1}{c|}{2010} & \multicolumn{1}{c|}{2011} & \multicolumn{1}{c|}{2012} & \multicolumn{1}{c|}{2013} \\
\hline WNI L & $8,930,485$ & $9,947,711$ & $10,531,907$ & $12,685,961$ & $12,045,359$ \\
\hline WNI P & $5,011,261$ & $5,913,455$ & $6,189,174$ & $3,445,310$ & $1,764,245$ \\
\hline WNA L & 43,629 & 52,938 & 56,298 & 121,136 & 54,402 \\
\hline WNA P & 10,594 & 18,614 & 21,620 & 15,828 & 14,432 \\
\hline JUMLAH & $13,995,969$ & $15,932,718$ & $16,798,999$ & $16,268,235$ & $13,878,438$ \\
\hline
\end{tabular}

Sumber : Ditjen Binwasnaker, Kemenakertrans, 2014

Kedua, besarnya proporsi jumlah penduduk usia produktif (15-60 tahun) dan penduduk usia muda (10-24 tahun) sampai dengan sekitar tahun 2030. Kondisi ini berdampak pada menurunnya angka ketergantungan (dependency ratio) dan sangat berdampak positif pada pembangunan ekonomi. Sekarang ini Indonesia sedang menikmati era "bonus demografi". Sedangkan tahun 2020-2035 Indonesia akan mengalami masa "window of opportunity" yaitu masa di mana "dependency ratio" berada pada posisi sangat rendah. Setelah 2035 "dependency ratio" akan kembali meningkat. Oleh karena itu, Indonesia harus melakukan investasi secara efektif dan efisien dalam SDM, terutama kelompok usia muda jika tidak ingin "window of oportunity" tersebut berubah menjadi "door to disaster". Investasi yang efektif, efisien dan berkualitas misal di bidang kesehatan termasuk hasilnya kesehatan reproduksi, pendidikan, dan juga pelatihan untuk penduduk usia muda (10-24 tahun). Kesehatan kelompok generasi muda terutama terkait dengan perilaku seksual berisiko, merokok, alkohol dan obatobatan terlarang sangat memprihatinkan. Sedangkan sebagian besar angkatan kerja pada saat ini bekerja pada usaha kecil yang memang tidak memerlukan keahlian kualitas yang tinggi, seperti terlihat pada Tabel 2 berikut.

Tabel 2. Keadaan Tenaga Kerja Menurut Klasifikasi Perusahaan 2009-2013

\begin{tabular}{|l|r|r|r|r|r|}
\hline & \multicolumn{1}{|c|}{$\mathbf{2 0 0 9}$} & $\mathbf{2 0 1 0}$ & \multicolumn{1}{c|}{$\mathbf{2 0 1 1}$} & $\mathbf{2 0 1 2}$ & $\mathbf{2 0 1 3}$ \\
\hline KECIL & 155,008 & 158,912 & 165,654 & 161,124 & 169,572 \\
\hline SEDANG & 39,301 & 41,641 & 42,204 & 42,559 & 44,330 \\
\hline BESAR & 14,504 & 15,994 & 17,222 & 18,956 & 24,971 \\
\hline JUMLAH & 208,813 & 216,547 & 225,080 & 222,639 & 238,873 \\
\hline
\end{tabular}

Sumber : Ditjen Binwasnaker, Kemenakertrans, 2014.
Ketiga, Indonesia memiliki jumlah dan proporsi penduduk usia lanjut ( di atas 60 tahun) akan mengalami peningkatan yang sangat pesat setelah tahun 2030 . Pada tahun 2050 jumlah penduduk lanjut usia di Indonesia hampir 80 juta jiwa. Mereka terdiri dari sekitar 36 juta berusia 60-69 tahun, 32 juta berusia 70-79 tahun dan 11,8 juta berusia di atas 80 tahun. Pemerintah sangat perlu mengembangkan kebijakan komprehensif untuk penduduk lanjut usia sejak saat ini jika tidak ingin memiliki persoalan sosial ekonomi yang kompleks dimasa mendatang. Program SJSN yang akan diimplementasikan penuh tahun 2019, misalnya, harus benarbenar dirancang dengan memperhatikan aspek perubahan struktur umur, pola penyakit dan struktur sosial yang ada di masyarakat. Karena jika tidak, maka program tersebut akan merupakan bom waktu persoalan ekonomi bangsa yang bisa meledak di masa mendatang.

Keempat, meningkatnya proporsi penduduk daerah perkotaan (urbanisasi) dari kondisi saat ini sekitar 50 persen dari jumlah seluruh penduduk menjadi sekitar 75 persen tahun 2050. Tantangan dalam perkembangan urbanisasi Indonesia yang menjadi perhatian oleh pemerintah adalah pesatnya perkembangan dan pertumbuhan kota metropolitan dan kota besar yang jauh melampaui kota-kota sedang dan kecil. Akibatnya penduduk desa yang ingin pindah ke daerah perkotaan lebih banyak langsung menuju ke kota metropolitan dan besar daripada menuju kota sedang dan kecil. Kejadian ini menimbulkan banyak persoalan sosial budaya di kota metropolitan dan kota besar. Di samping itu perkembangan yang tidak terkendali dari kota metropolitan dan kota besar akan berdampak buruk pada persoalan lingkungan dan dapat menimbulkan ekonomi tinggi. Sebaliknya daerah pedesaan kurang berkembang dan keadaan ini berdampak pada menurunnya produksi pangan yang pada akhirnya akan berdampak pada semakin banyaknya masalah penduduk yang ada di kota dan 
berhubungan dengan hal-hal kriminalitas, pemukiman kumuh, anak jalanan dan makin berkembangnya sektor informal yang tidak akan menunjang pertumbuhan ekonomi seperti yang diharapkan.

Di samping ke empat mega trend di atas, hal yang perlu dikelola dengan baik dan diintegrasikan ke dalam kebijakan pembangunan tingkat nasional, dan isu kependudukan lainnya misalnya seperti: masyarakat adat, penduduk dengan kecacatan fisik dan mental, serta penduduk dengan kebutuhan khusus, tentu juga perlu mendapatkan perhatian dari pemerintah.

\section{B. Menangkar Masa Depan}

Persoalan sosial kependudukan dan ketenagakerjaan khususnya di Indonesia tentunya akan semakin kompleks di masa mendatang. Penduduk Indonesia tidak saja masih akan terus bertambah namun berbagai dinamika kependudukan seperti perubahan struktur umur dan juga pola distribusi serta mobilitas diikuti dengan dinamika kualitas akan membutuhkan penanganan yang serius. Tanpa adanya sikap keseriusan maka potensi penduduk sebagai modal pembangunan akan tinggal sebagai jargon semata. Namun sebaliknya hasil pembangunan juga hanya akan dinikmati hanya oleh segelintir penduduk sehingga kesenjangan pendapatan akan semakin melebar dan besar, yang bukan tidak mungkin akan berujung pada perpecahan dan kerawanan sosial lainnya. Selain itu masalah pengangguran yang saat ini menjadi persoalan utama bidang ketenagakerjaan memerlukan perhatian lebih serius.

Berdasar dinamika kependudukan yang ada maka paling tidak ada beberapa persoalan pokok yang harus diantisipasi. Pertama, penduduk Indonesia masih akan terus bertambah. Hingga tahun 2050 penduduk Indonesia diperkirakan akan memiliki jumlah menjadi 320-370 juta tergantung bagaimana keberhasilan KB.
Perbedaan 50 juta itu juga merupakan angka yang sangat bermakna untuk keberadaan akan kelangsungan kehidupan bumi. Saat ini saja carrying capacity bumi sudah sekitar 1,8 kali dari yang seharusnya. Persoalan yang berhubungan dengan keadaan lingkungan perlu menjadi perhatian.

Kedua, saat ini Indonesia sedang menikmati "bonus demografi" sampai dengan tahun 2035. Persoalan kualitas penduduk terutama generasi muda harus menjadi perhatian utama dalam hubungan dengan suatu kebijakan ketenagakerjaan. Melihat perkembangan perusahaan yang tentunya memerlukan tenaga berkualitas seperti terlihat pada Tabel 3 di bawah ini.

Tabel 3. Kondisi Ketenagakerjaan Menurut Status Perusahaan 2009-2013

\begin{tabular}{|c|r|r|r|r|l|}
\hline & \multicolumn{1}{|c|}{$\mathbf{2 0 0 9}$} & \multicolumn{1}{|c|}{$\mathbf{2 0 1 0}$} & \multicolumn{1}{|c|}{$\mathbf{2 0 1 1}$} & \multicolumn{1}{|c|}{12} & $\mathbf{2 0 1 3}$ \\
\hline SWASTA & 173,028 & 180,735 & 187,420 & 80,749 & 03,567 \\
\hline PMDN & 22,917 & 20,884 & 21,555 & 18,944 & 18,557 \\
\hline PMA & 7,996 & 9,110 & 9,585 & 7,819 & 13,509 \\
\hline $\begin{array}{c}\text { JOIN } \\
\text { VENTURA }\end{array}$ & 2,872 & 5,798 & 6,520 & 4,577 & 3,240 \\
\hline JUMLAH & 206,813 & 216,527 & 225,080 & 12,089 & 38,873 \\
\hline
\end{tabular}

Sumber : Ditjen Binwasnaker, Kemenakertrans, 2014.

Ketiga, setelah tahun 2030 Indonesia mulai memasuki era penduduk lanjut usia. Indonesia mulai menghadapi lansia boom tahun 2030. Saat ini jumlal lansia sekitar 20 juta yang diperkirakan akan menjadi sekitar 25 juta pada tahun 2030 dan pada tahun 2050 angkanya mendekati 70 juta jiwa. Suatu kebijakan yang komprehensif sangat diperlukan jika Indonesia tidak menginginkan munculnya masalah serius sehubungan dengan isu lansia.

Keempat, distribusi atau persebaran penduduk Indonesia masih terkonsentrasi di pulau Jawa, Bali dan Sumatera dengan proporsi mereka yang tinggal diperkotaan akan terus meningkat. Saat ini penduduk tinggal di perkotaan sekitar $50 \%$ dari jumlah penduduk yang ada di mana di pulau Jawa angkanya sudah mendekati 70\%. Pada tahun 2050 diperkirakan penduduk tinggal di perkotaan mendekati $70 \%$ dan di pulau Jawa mendekati $90 \%$. 
Jawa akan menjadi pulau kota. Apakah kecenderungan ini yang memang diinginkan, ataukah harus dilakukan pengalihan lokasi industri ke luar pulau Jawa agar laju urbanisasi di Jawa bisa lebih dikurangi? Bagaimana dengan kebutuhan penyediaan pangan, karena pulau Jawa merupakan lokasi yang sangat cocok untuk tanaman pangan? Strategi apa yang harus disiapkan untuk subsitusi lokasi pangan di Jawa ke pulau lainnya? Dengan kondisi jumlah penduduk yang akan terus bertambah dan penyusutan lahan pertanian di pulau Jawa maka fenomena impor bahan pangan, seperti yang sudah terjadi sekarang ini, menjadi tidak terelakan atau bahkan mungkin akan lebih memprihatinkan. Apakah memang keadaan seperti ini yang diinginkan?

Dinamika kependudukan di atas ditambah dengan aspek kualitas serta pembangunan ekonomi sangat terkait satu dengan yang lainnya, sehingga juga perlu dirumuskan kebijakan terpadu dan terarah dalam upaya meningkatkan kesejahteraan penduduk dan juga mencoba membuka lapangan kerja yang mungkin tersedia, tentu dengan mempertimbangkan kualitas pekerja yang ada.

Kualitas penduduk Indonesia perlu ditingkatkan sesuai dengan kemampuan yang ada. Kesehatan dan pendidikan lebih diperhatikan dengan cara mengalokasikan anggaran yang lebih memadai kearah dua sektor utama peningkatan mutu SDM tersebut. Kebijakan ini dimaksudkan agar penduduk yang ada dapat menjadi "aset" pembangunan, bukan hanya sekedar menjadi beban. Jumlah penduduk harus tetap dikendalikan melalui pengendalian kelahiran, agar beban pembangunan tidak menjadi semakin berat pada mendatang.

Pembangunan ekonomi yang tanpa didukung kualitas yang memadai sifatnya tidak akan berkelanjutan. Sebaliknya, peningkatan kualitas penduduk tidak akan terjadi jika pertumbuhan ekonomi tidak ada. Artinya pertumbuhan ekonomi dan peningkatan kualitas penduduk akan sulit dilaksanakan jika jumlah penduduk semakin besar dan sudah terlanjur rendah kualitasnya. Apalagi bila pertumbuhan ekonomi hanya dimungkinkan melalui peningkatan angkatan kerja yang bekerja pada sektor-sektor usaha yang formal seperti yang terjadi pada saat ini.

Di samping persoalan kualitas penduduk, persoalan pengendalian jumlah penduduk, melalui program $\mathrm{KB}$ dan distribusi penduduk melalui transmigrasi yang dikaitkan dengan pembangunan wilayah, juga harus menjadi perhatian. Keberhasilan program KB dan program transmigrasi pada dasawarsa 1970-an dan 1990-an perlu tetap dijadikan sebagai landasan kebijakan. Jika pada tahun 2000, Indonesia bisa menghindari tambahan 80 juta penduduk (mengacu pada proyeksi yang dilakukan oleh almarhum Prof. Widjojo Nitisastro) maka tahun 2050 Indonesia harus bisa mencapai sasaran jumlah penduduk 320 juta dan bukan sebesar 370 juta seperti yang dikuatirkan sesuai proyeksi yang pernah dilakukan saat ini.

Lembaga yang mengurusi program $\mathrm{KB}$ harus diperkuat agar program ini kembali mendapat perhatian dari seluruh sektor pembangunan. Kelembagaan yang mengurus program $\mathrm{KB}$ harus kembali menjadi lembaga yang disegani. Program $\mathrm{KB}$ harus secara sistematis masuk dalam agenda pembahasan dalam sidang-sidang kabinet dan menjadi salah satu aspek yang harus dipantau serta dievaluasi secara berkelanjutan dan ketat oleh pemerintah. Sedangkan cara mengantisipasi persoalan ketenagakerjaan, lembaga khusus yang menangani persoalan ketenagakerjaan perlu dikaji ulang. Tumpang tindih dan adanya lembaga yang tidak diperlukan, seperti BNP2TKI, seharusnya dihapus. Kementerian Tenaga Kerja tanpa adanya transmigrasi seharusnya mengurus semua persoalan menyangkut ketenagakerjaan; termasuk tenaga kerja Indonesia (TKI) yang mencari nafkah di luar negeri. 
Demikian pula strategi dalam hal pembangunan ekonomi harus benar-benar memperhatikan dinamika kependudukan. Harus dihindari pencapaian sasaran laju pertumbuhan ekonomi sesaat dan hanya dinikmati hanya oleh segelintir orang. Kesenjangan, baik yang bersifat antar wilayah maupun latar belakang sosial ekonomi, akan berdampak buruk dalam jangka panjang. Dinamika kependudukan saat ini memang sangat kurang terfleksi dalam strategi pembangunan ekonomi nasional seperti misalnya dan RPJP. Kepedulian aspek kependudukan dalam setiap rancangan pembangunan perlu mendapat perhatian serius dan mendalam.

\section{Alternatif Kebijakan}

Berdasar dinamika perkembangan kependudukan dan ketenagakerjaan yang telah diuraikan dalam pembahasan diatas, terdapat beberapa pilihan kebijakan yang bisa diambil untuk menghadapi masa mendatang, kebijakan itu dapat diuraikan dalam pembahasan berikut ini.

Pertama, dalam hal menghadapi ' 'bonus demografi', yang segera terjadi, perlu disiapkannya suatu kebijakan yang menyangkut perluasan kesempatan kerja di dalam negeri. Sekaligus disiapkan pula pengembangan sikap kewirausahaan agar tenaga kerja terutama usia produktif yang ada mampu menyiapkan pekerjaaan sendiri. Upaya untuk mengirim tenaga kerja Indonesia keluar negeri seyogyanya bukan merupakan alternatif yang dipilih.

Kedua, dengan semakin bertambah besar penduduk lanjut usia, perlu segera dilakukan tindakan untuk membuat suatu 'old-aged friendly city' di berbagai tempat. Perkotaan yang ramah pada orang tua sehingga kelompok lanjut usia ini bisa hidup dan beraktivitas secara nyaman perlu segera ditumbuhkan. Pada saat ini sudah banyak kota-kota di Indonesia yang ramah lingkungan, atau biasa disebut "environmental friendly cities" tetapi belum pernah terpikirkan untuk mengusa- hakan adanya "perkotaan yang ramah pada orang tua',

Ketiga, Konsentrasi penduduk yang terpusat pada daerah-daerah perkotaan di pulau-pulau Jawa, Bali, dan Sumatera harus diperhatikan serius. Kesemrawutan lalu lintas, berkembangnya daerah-daerah kumuh (slum areas) dan kriminalitas perkotaan akan mewarnai kehidupan kota-kota besar di tiga pulau tersebut. Ditambah dengan persoalan polusi udara dan pencemaran air minum, kebijakan yang terpadu diantara para pengambil kebijakan di bidang perkotaan dan kependudukan perlu dipikirkan serta ditindaklanjuti secara lebih hati-hati dan secara seksama.

Keempat, semua pilihan kebijakan yang diusulkan tersebut perlu dilandasi dengan adanya kelembagaan yang kuat serta efektif. Suatu kelembagaan di bidang kependudukan dan keluarga berencana yang legalitasnya diakui dan diikuti segenap jajaran pemerintahan. Pimpinan nasional harus merumuskan kelembagaan di pemerintahan mendatang agar bisa memberikan kewenangan yang lebih bagi perkembangan kebijakan di bidang kependudukan dan KB.

\section{Penutup}

Dinamika pada kependudukan dan ketenagakerjaan yang ada perlu kembali diletakkan di dalam kerangka dasar pembangunan nasional dan dijadikan acuan oleh seluruh sektor seperti halnya dalam GBHN dan Repelita pada masa lalu. Presiden selaku kepala pemerintahan perlu dibantu oleh mereka yang benarbenar ahli dalam bidang kependudukan dan ketenagakerjaan, serta memiliki kemampuan dalam mengelola ekonomi makro dari kaca mata kependudukan. Presiden perlu memiliki penasehat di bidang kependudukan. Penasehat ini dapat bekerjasama dengan berbagai lembaga untuk melakukan kajian, analisis atau simulasi kebijakan-kebijakan yang memang sangat diperlukan. 
Melalui berbagai upaya di atas, Indonesia diharapkan dapat mengubah paradigma pembangunan dengan lebih mengedepankan aspek kependudukan dan ketenagakerjaan sebagai dasar strategi pembangunan paska 2015 sebagaimana diamanatkan dalam dokumen Rio+20 dan laporan High Level Panel of Eminent Persons (HLPEP) yang menjadi acuan dari strategi pembangunan berkelanjutan (sustainable development). Dengan berbagai upaya di atas Indonesia akan dapat meningkatkan kesejahteraan penduduknya secara berkelanjutan, bukan sesaat, dan terhindar dari fenomena Failed State (Negara Gagal).

\section{Daftar Pustaka}

Kantor Menteri Negara Kependudukan/ Badan Keluarga Berencana Nasional, 1995, 25 tahun Gerakan Keluarga Berencana Nasional

Kementerian Perencanaan Pembangunan Nasional/Bappenas, Bank Dunia, Australian AID, the Swiss Economic Development Cooperation, 2013, Indonesia, the Rise of Metropolitan Regions: Towards Inclusive and Sustainable Regional Development

USAID dan BKKBN, 2006, 35 Years Commitment to Family Planning in
Indonesia : BKKBN and USAID's Historic Partnership

BPS, BKKBN, Kementerian Kesehatan, Measure DHS ICF Internasional, 2013, Laporan Pendahuluan Survey Demografi dan Kesehatan Indonesia, 2012

Kementerian Perencanaan Pembangunan Nasional/Bappenas, 2010, Peta Jalan Percepatan Pencapaian Tujuan Pembangunan Millenium di Indonesia

Kementerian Perencanaan Pembangunan Nasional/Bappenas, 2012, Laporan Pencapaian Tujuan Pembangunan Millenium di Indonesia 2011

John Bongaarts, 2013, Population Dynamics and Development Opportunities. Paper disampaikam pada pertemuan internasional ahli kependudukan yang diselenggarakan oleh BKKBN dan UNFPA Indonesia, Maret 2013

UNFPA, 2013, Reliazing the Future We Want For All: the post 2015 Development Agenda, A Call to Integrate Population Dynamics into the Post 2015 Development Agenda, Recommendations of the Global Thematic Consultation on Population Dynamics and the Post 2015 Development Agenda. Outcome Document 14 March 2013. 